Borneo Journal of Sciences \& Technology, 3(2): 39-44

DOI: http://doi.org/10.3570/bjost.2021.3.2-07

e-ISSN: 2672-7439

(C) 2018, UCTS Publisher.

Submitted: $11^{\text {th }}$ February 2021

Accepted: $15^{\text {th }}$ July 2021

Published: $31^{\text {st July } 2021}$

\title{
A Conceptualize of Cultural Ecosystem Service Recreational Benefits: A Systematic Review Method
}

\author{
*Kaede Chan Lip Chung, Andy Russel Mojiol and Kamlisa Uni Kamlun \\ Forestry Complex, Faculty of Science and Natural Resource, Universiti Malaysia Sabah (UMS), \\ 88400, Kota Kinabalu, Sabah, Malaysia
}

\begin{abstract}
A cultural ecosystem service is part of ecosystem service that beneficial human from intangible and nonconsumable welfare such as recreational values. However, these kinds of intangible values are difficult to conceptualize in any framework. So, this paper aims to conceptualize the cultural ecosystem services of recreational benefits by reviewing respective journal papers. In this study, a systematic review approach applies to a total of 38 journal papers. The Common International Classification of Ecosystem Services V5.1 classification system matches the fundamental nature of this world's reality and assists with the 8-dimension value of the environment, a theory from one of the published journals. Further, the built conceptual framework shows that "preference" is the most significant factor in a conceptual framework because it can influence "truth-telling" and "honest" during answering questionnaires or decision-making. So, further study is needed on this aspect to clarify unanswered questions in this field.
\end{abstract}

Keywords: Cultural Ecosystem Services (CES), Common International Classification of Ecosystem Service (CICES V5.1), Dimension value of Environmental decision-making

\section{INTRODUCTION}

A cultural ecosystem service (CES) is part of ecosystem service (ES) function as serving human welfare from an intangible product such as "experience," "feel relaxing," and non-consumable product [1];[4];[5]. In this global era, various typologies that often use to indicate the values of CES, such as Millennium Ecosystem Assessment (MEA) [5], The Economics of ecosystem and biodiversity (TEEB) [7], and Common International Classification of Ecosystem Services (CICES) [6]. However, literature shows that CICES is more comprehensive to access the natural environment's benefits [3]. CES provides direct, indirect, non-use, and option-use values [2]. So, the argument exists between using MEA, TEEB, and CICES in CES studies.

Furthermore, CES is difficult to quantify by a practical conceptual framework or model through either personal or holistic welfare [1];[4]. Hence, CES provision intangible benefits to human welfare, such as "experience." This literature [1] clarified that CES such intangible "values" observe through eight dimensions and the use of value for the decision-making process. As stated by [1], preference sometimes influences principle and virtue because different personalities have other choices and attitudes. When asking about recreational benefits, the respondents might prioritize its will rather than focus (truth-telling) or integrity (honest). Moreover, a systematic review is an effective way to study CES even it is the most challenging approach [2].

Therefore, this study aims to conceptualize CES's recreational benefits by reviewing the CICES V5.1 [6] and [1] conceptual framework to encompass CES values. Further, (Chan et al., 2012) 8-dimension value of environment theory helps explain decision-making and its help to compass the conceptual framework flow.

\section{MATERIALS AND METHODS}

\section{Method of review paper:}

In this study, few search engines need to acquire information to understand CES and its benefits better. Hence, both "Science Direct website (https://www.sciencedirect.com/) and Google Scholar (https://scholar.google.com/) selected as the apparatus for the systematic review method. Since this study focuses on CES, the keywords that enter the journals from the search engines shown in Table 1, each 
A conceptualize of Cultural Ecosystem Service Recreational Benefits: A Systematic Review Method.

keyword represents a different description and defines

Table 1: Terminology of searching CES this study's field. The illustration below showed that:

\begin{tabular}{|c|c|}
\hline Keywords & Description \\
\hline Cultural ecosystem services & $\begin{array}{l}\text { The ecosystem cultural utilities beneficial intangible, } \\
\text { invisible, and non-consumable to a person or holistic welfare } \\
\text { (Daniel et al., 2012) }\end{array}$ \\
\hline Cultural ecosystem services + urban & $\begin{array}{l}\text { The urban ecosystem is functional as a cultural benefit } \\
\text { for human welfare. Modified from (Bolund \& Hunhammar, } \\
\text { 1999) }\end{array}$ \\
\hline Cultural ecosystem services + recreation & $\begin{array}{l}\text { The cultural ecosystem services beneficial human } \\
\text { recreational aspects. Modified from (Haines-Young \& } \\
\text { Potschin, 2018) }\end{array}$ \\
\hline $\begin{array}{l}\text { Cultural ecosystem services }+ \text { urban }+ \\
\text { recreation }\end{array}$ & $\begin{array}{l}\text { The urban cultural ecosystem services beneficial human } \\
\text { recreational aspects. Modified from (Bolund \& Hunhammar, } \\
\text { 1999; Haines-Young \& Potschin, 2018) }\end{array}$ \\
\hline $\begin{array}{l}\text { Systematic review }+ \text { cultural ecosystem } \\
\text { services }\end{array}$ & $\begin{array}{l}\text { The method of systematic reviewing published papers } \\
\text { for cultural ecosystem services. Modified from (Christie et } \\
\text { al., 2012) }\end{array}$ \\
\hline
\end{tabular}

Further, the keywords in Table 1 had entered into the search engines to review the published paper needed for this study, since CES's terminology as the ecosystem cultural utilities beneficial intangible, invisible, and non-consumable to a person or holistic welfare [4]. From selected and filtering the published papers from the year 2016 until 2020, there is a total of 38 articles selected to study the benefits of CES, including the main document for conceptualized the CES $[1,6]$.

Subsequently, from the paper [3], the investigators of this study understand that other researchers often use few typologies in their CES studies, such as MEA, TEEB, and CICES. However, after the reviewed documents, the investigator applied the theoretical table in paper [3] to compare CICES V5.1, MEA, and TEEB. This study found that CICES V5.1 is more comprehensive to access CES benefits than MEA and TEEB. The MEA and TEEB classified the CES into few categories, such as recreation and ecotourism benefits and more. But the CICES V5.1 detailed the CES benefits shown in Figure 1.

\section{RESULTS AND DISCUSSION}

This study had worked out a conceptual framework combining literature papers CICES V5.1 [6, 1], 8dimension values of environmental to show the possible flow of CES values in the natural environment. Figure 1 shows that CES values classify into three significant divisions: outdoor/ direct interaction, indirect/ indoor interaction, and others. Direct interaction is a kind of benefit that humans can gain through either physical or experiential interaction. While indoor interaction is the net flow of intellectual benefits to human welfare by after experience through the nature-based-for example, humans have been inspired through the art and nature of the ecosystem. Hence, the difference between non-use value and option use-value is non-use value is the current value in the environment, such as rare species of flora and fauna. In contrast, option usevalue is the kind of value that humans save for future usage. For example, biodiversity is already of value to human welfare, and humans tried to sustain the biodiversity to support the ecosystem balance.

Furthermore, classes under direct interaction are recreational and ecotourism, knowledge system, aesthetic, cultural diversity, and inspiration. As mentioned earlier, humans can directly gain benefits through physical and experiential interaction in the outdoor business. Hence, recreation is beneficial when humans have direct interaction with the ecosystem during their leisure time. From the perspective of the knowledge system, aesthetic, cultural diversity, and inspiration benefits, other benefits from physical and experiential interaction to the ecosystem include scientific value, educational, cultural heritage, and aesthetics. Since the ecosystem produces comfortable, relaxation, and tranquillity during physical and experiential interaction, it also inspires humans to study the traditional knowledge of nature and create arts.

Moreover, indirect interaction such as spiritual, religious, and entertainment the net benefits supports by direct interaction such as scientific and educational values. Humans yet to recognize the intellect benefits through the experience during the time spent in the ecosystem. However, people only realized the appearance of these kinds of value when they had depth investigation on it, such as reviewing papers. However, there is an argument between classes of "entertainment" under the spiritual and religious groups. CICES V4.3 [3] initially classified underclasses of direct interaction, while in CICES V5.1 [6], entertainment reclassified under indirect division because philosophers believe 40 
A conceptualize of Cultural Ecosystem Service Recreational Benefits: A Systematic Review Method.

that entertainment is a kind of culture that should save for the future generation. In this study, the philosopher agrees with this statement because by looking at the culture in Japan. In a particular rural-urban area of Japan, the relationship between spiritual and religious are strong with the ecosystem. For example, the "Kanda Festival" the celebration of the most powerful shrine in Japan. The Japanese gathering at the Kanda Myojin Shrine to bless wealth and good fortune for the Japanese [8]. Therefore, this kind of entertainment classification exists in a specific country and depends on their culture; another example such as China and Korea had "Mooncake festival" and "Chuseok," "thanksgiving" in western countries. All these festivals are having the similarity of celebrating the ethics and moral values educated by their religion.

Subsequently, the terminology of value is still a discussion and argument among the philosophers [1]. Since CES is a kind of intangible product of the ecosystem, it isn't easy to describe the type of values given to human welfare. However, thanks to philosophers [1], CES's benefits classify into eight dimensions. These dimensions clarified the decisionmaking process and the factors influencing people's freedom of choice using the environment. Figure 1 shows that the values dimension consisting of human psychological behaviour (preference vs principles vs virtue) and value mediated (market mediate vs nonmarket mediate). Further, the value also includes constituency (individual vs holistic/group) and orientation (self-oriented vs other-oriented). Moreover, the eight dimension values also include fundamental nature of reality (experiential[physical] vs. metaphysical), method of evaluation (instrumental vs. inherent), transformation value (transformative vs. nontransformative), and object of beneficial (anthropocentric [human] vs. biocentric [non-human]).

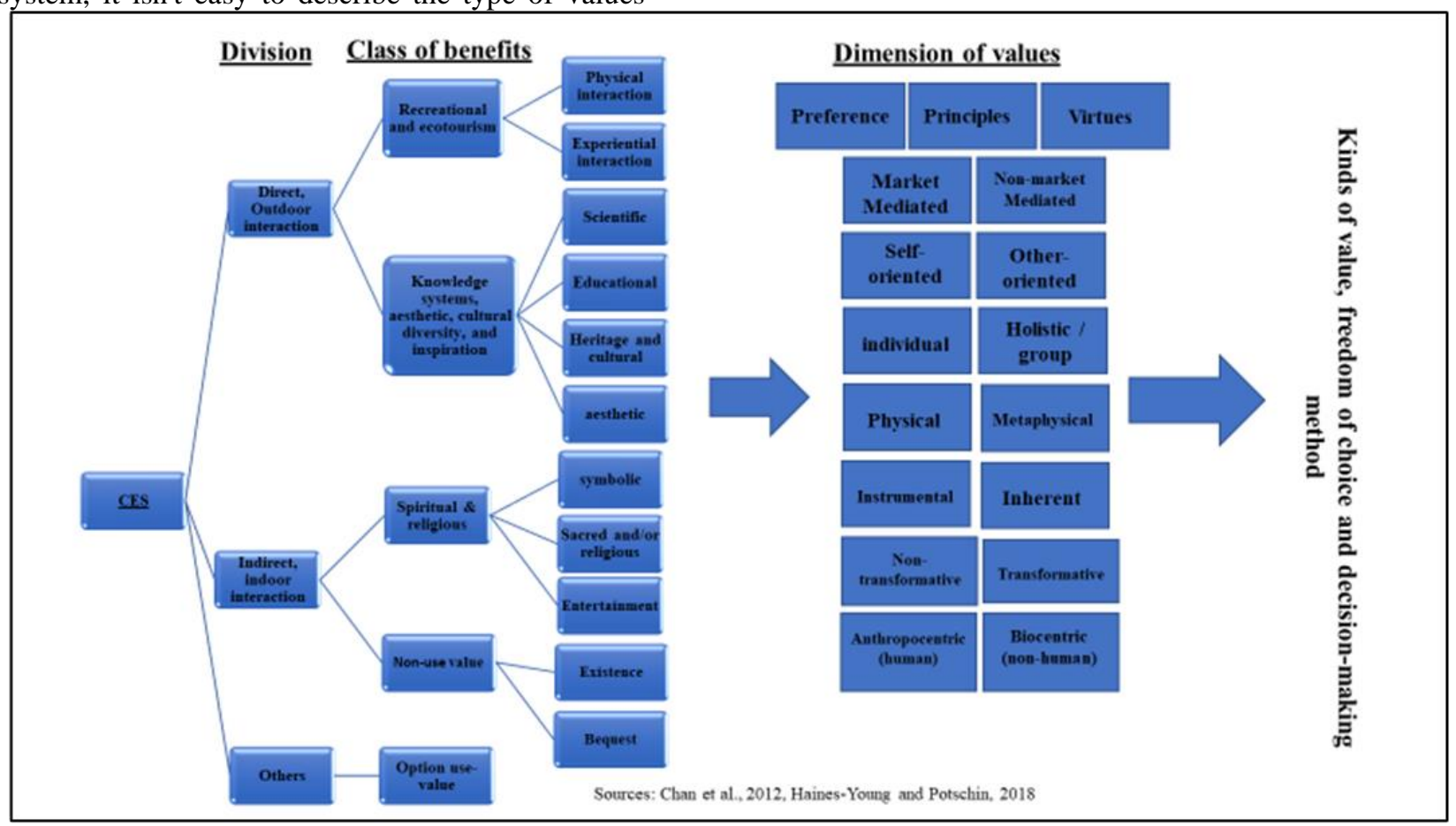

Figure 1: Conceptual framework of classification CES values

\section{CONCLUSION}

In conclusion, cultural ecosystem services "values" are classified into three subdivisions: outdoor interaction, indoor interaction, and other interaction. From figure 1, outdoor business is more beneficial to human welfare, such as recreational, aesthetic, knowledge, and more. Simultaneously, indoor interaction indirectly helps human welfare, such as spiritual, religious, and non-use value. Meanwhile, certain benefits that underrate classified as others. So, more studies are needed for the future to discover the unclassified benefits from the CES.

Finally, a human being's freedom of choice to use the cultural ecosystem services depends on the 8dimension factors such as human psychological behaviour, value mediated, constituency and orientation, fundamental nature of reality, method of evaluation, and value of transformation, and object of beneficial. However, human "preference" is the primary 
A conceptualize of Cultural Ecosystem Service Recreational Benefits: A Systematic Review Method.

factor influence the choice because human might prioritize "favourite choice" rather than "truth-telling" or "honest" when an option given to them.

\section{ACKNOWLEDGMENT}

The author would like to express their deepest gratitude to the Faculty of Science and Natural Resources to grant permission to execute our study to review CES papers. A million thanks to the author's friends and family to support this research and proofread the article. Moreover, a special thanks to Sabah state government scholarship funding and the University of Malaysia Sabah for grant provision FRG0547-2020 in this study.

\section{REFERENCES}

[1] Chan, K. M. A., Satterfield, T., \& Goldstein, J. (2012). Rethinking ecosystem services to better address and navigate cultural values. Ecological Economics, 74 , 8-18. https://doi.org/10.1016/j.ecolecon.2011.11.011

[2] Christie, M., Fazey, I., Cooper, R., Hyde, T., \& Kenter, J. O. (2012). An evaluation of monetary and non-monetary techniques for assessing the importance of biodiversity and ecosystem services to people in countries with developing economies. Ecological Economics, 83(2012), 67-78. https://doi.org/10.1016/j.ecolecon.2012.08.012

[3] Czúcz, B., Arany, I., Potschin-Young, M., Bereczki, K., Kertész, M., Kiss, M., ... HainesYoung, R. (2018). Where concepts meet the real world: A systematic review of ecosystem service indicators and their classification using CICES.
Ecosystem Services, 29, 145-157. https://doi.org/10.1016/j.ecoser.2017.11.018

[4] Daniel, T. C., Muhar, A., Arnberger, A., Aznar, O., Boyd, J. W., Chan, K. M. A., ... Von Der Dunk, A. (2012). Contributions of cultural services to the ecosystem services agenda. Proceedings of the National Academy of Sciences of the United States of America, 109(23), 8812-8819. https://doi.org/10.1073/pnas.1114773109

[5] Duraiappah, A. K., Naeem, S., Agardy, T., Ash, N. J., Cooper, H. D., Díaz, S., ... Millennium Ecosystem Assessment. (2005). Ecosystems and human well-being. In Ecosystems (Vol. 5). https://doi.org/10.1196/annals.1439.003

[6] Haines-Young, R., \& Potschin, M. (2018). CICS V5. 1. Guidance on the Application of the Revised Structure. Fabis Consulting, (January), 53.

[7] Heidi Wittmer (UFZ), Hugo van Zyl (Independent Economic Researchers), Claire Brown (UNEP WCMC), Julian Rode (UFZ), Ece Ozdemiroglu (Eftec), Nick Bertrand (UNEP), Patrick ten Brink (IEEP), Andrew Seidl (Colorado State University), Marianne Kettunen (IEEP), Leonardo Mazza (IEEP), Florian Manns (UFZ), Jasmin Hundorf (UNEP), Isabel Renner (GIZ), Strahil Christov (DG Environment), Pavan Sukhdev (GIST). (2013) The Economic and Ecosystems and Biodiversity (TEEB) (2013) 'Manual for TEEB Country Studies,' pp. 1-94. DOI: http://www.teebweb.org/media/2013/10/TEEB_Gu idanceManual_2013_1.0.pdf.

[8] Japan Guide.com. (2020). Tokyo Travel: Kanda Matsuri (Kanda Festival). [Website] Retrieved from https://www.japan-guide.com/e/e3073.html 
A conceptualize of Cultural Ecosystem Service Recreational Benefits: A Systematic Review Method.

\section{Appendix 1}

Table 2: List of Journal selected for reviewing the paper

\begin{tabular}{|c|c|c|c|}
\hline \multirow[t]{2}{*}{ Author (Year) } & \multicolumn{3}{|c|}{ Assessment } \\
\hline & $\underset{\Sigma}{\mathbb{1}}$ & 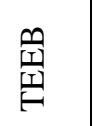 & 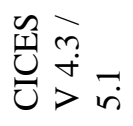 \\
\hline \multicolumn{4}{|l|}{ (Costanza et al., 1997) } \\
\hline \multicolumn{4}{|l|}{ (Bolund and Hunhammar, 1999) } \\
\hline \multicolumn{4}{|l|}{ (De Groot et al., 2002) } \\
\hline \multicolumn{4}{|l|}{ (Sanesi and Chiarello, 2006) } \\
\hline (Chan et al., 2012) & 1 & & \\
\hline (Daniel et al., 2012) & 1 & 1 & \\
\hline (Milcu et al., 2013) & 1 & 1 & \\
\hline \multicolumn{4}{|l|}{ (Nowak and Forest, 2013) } \\
\hline (Brancalion et al., 2014) & 1 & & \\
\hline (Van Berkel and Verburg, 2014) & 1 & & \\
\hline (Darvill and Lindo, 2016) & 1 & & \\
\hline (Larson et al., 2016) & 1 & 1 & 1 \\
\hline (Maraja et al., 2016) & 1 & & \\
\hline (Nesbitt et al., 2017) & 1 & & \\
\hline (Rall et al., 2017) & 1 & & \\
\hline (Stålhammar and Pedersen, 2017) & 1 & & \\
\hline (Ciftcioglu and Aydin, 2018) & 1 & 1 & \\
\hline (Graça et al., 2018) & 1 & & \\
\hline (Czúcz et al., 2018) & 1 & 1 & 1 \\
\hline (Ko and Son, 2018) & 1 & 1 & \\
\hline (Riechers et al., 2018) & 1 & 1 & \\
\hline (van Hardeveld et al., 2018) & 1 & & \\
\hline \multicolumn{4}{|l|}{ (Zwierzchowska et al., 2018) } \\
\hline (Charoenkit and Piyathamrongchai, 2019) & 1 & 1 & 1 \\
\hline (Cheng et al., 2019) & 1 & 1 & \\
\hline (Dou et al., 2019) & 1 & & \\
\hline (Miller and Montalto, 2019) & 1 & 1 & \\
\hline (Yang et al., 2019) & 1 & & \\
\hline (Amorim Maia et al., 2020) & 1 & & \\
\hline \multicolumn{4}{|l|}{ (Dade et al., 2020) } \\
\hline (Dou et al., 2020) & 1 & & \\
\hline (Elliott et al., 2020) & 1 & 1 & \\
\hline
\end{tabular}


A conceptualize of Cultural Ecosystem Service Recreational Benefits: A Systematic Review Method.

\begin{tabular}{|l|r|r|r|}
\hline (Filho et al., 2020) & 1 & 1 & \\
\hline (Kaltenborn et al., 2020) & 1 & 1 & \\
\hline (Kosanic and Petzold, 2020) & 1 & & \\
\hline (Kuldna et al., 2020) & & & \\
\hline (Rosehan et al., 2020) & 1 & 1 & \\
\hline (Wang et al., 2021) & 1 & & \\
\hline
\end{tabular}

